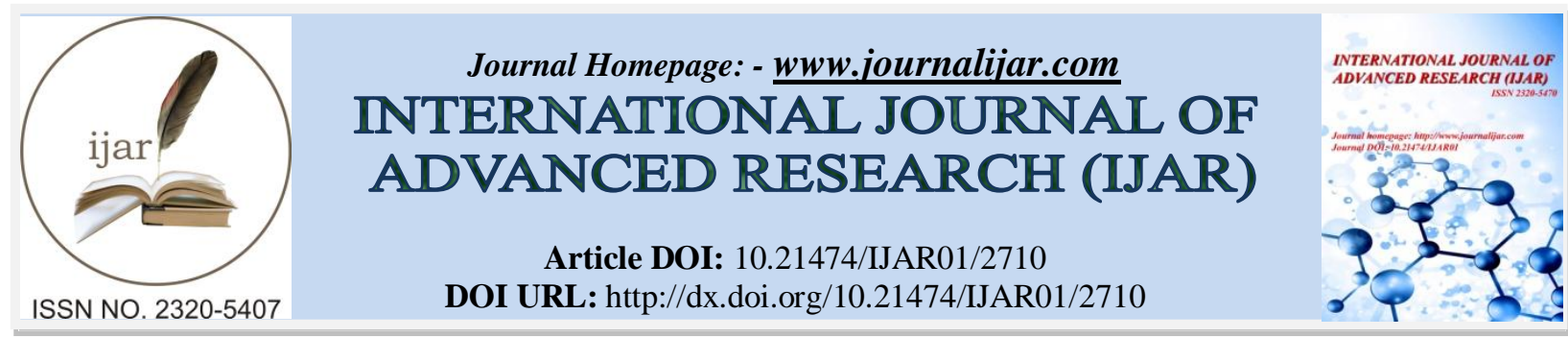

RESEARCH ARTICLE

\title{
PREVALENCE OF AGE-RELATED CATARACT AND CATARACT SURGERY IN A SAUDI ARABIAN ADULT POPULATION: PRINCE MOHAMMED BIN NASSER HOSPITAL EYE STUDY (JAZAN).
}

\author{
Mona Kenani, Reem Shajary Abdullah Khawaji, Sultan Bakri*, Abdulrahmanmakin, Azza Mohanna, \\ Marwah Abbas and Tahani Moafa.
}

Department of Ophthalmology, Prince Mohammed Bin Nasser Hospital,Jazan Saudi Arabia.

\section{Manuscript Info}

........................

\section{Manuscript History}

Received: 31 October 2016

Final Accepted: 01 December 2016

Published: December 2016

Key words:-

cataract, cataract surgery, Saudi Arabia.

\section{Abstract}

Introduction: Nowadays, world is suffering from the visual impairment with its primary cause as the age-related cataract. It is more prevalent in China which is most populous country of the world (Brian \& Taylor, 2001). But still, it is on the rise in the developed country like Saudi Arabia too

Methods: Study Design and Procedures: For Prince Mohammed bin Nasser Hospital Eye Study, we conducted a baseline assessment related to the ophthalmology from April 2015 to February 2016. We also followed the random sampling method while creating a sampling frame with the help of geographically demarcated clusters. The sample size was 500 people which were aged 45 years or above. The recruitment material was handed over to all the targeted communities three to seven days before the survey. Every survey participant was self-identified and the research considered all the ethical considerations related to the identities of respondents. The generic consent of all the survey respondents was taken before going ahead with the study.

Results and Discussion: Out of the 500 respondents, 496 (response rate, $99.2 \%$ ) carried out the eye examinations. Considering the data, the mean age of the survey respondents was $63.74+/ 11.289$ (median 62; age range 22-96 years); There was higher count of males with male-to-female ratio as 292:204. Here, p-value was 0.341 which is greater than 0.05

Conclusion:The chi-square test is not significant and the results are not occurring by chance. Moreover, there was further age and sex based studies for the types of cataracts.

Copy Right, IJAR, 2016,. All rights reserved.

\section{Introduction:-}

Nowadays, world is suffering from the visual impairment with its primary cause as the age-related cataract. It is more prevalent in China which is most populous country of the world (Brian \& Taylor, 2001). But still, it is on the rise in the developed country like Saudi Arabia too. Presently, surgery is considerable as the sole effectual treatment for cataract but still, it is not reasonable as it is very costly way to treatment in the developing nations (Rao, Khanna, $\&$ Payal, 2011). Moreover, cataract is considerable as a cause of the huge socioeconomic burdens. Studies from the US-based researchers stated that the total expense related to the age-related cataract is $\$ 5$ - $\$ 6$ billion every year in 
the USA (Richter, Chung, Azen, \& Varma, 2009). With the increase in the aged population, there is an increase in the age-related cataract and the relative socioeconomic burden (Klein, Klein, Lee, \& Gangnon, 2008).

There are estimations associated with the age-related cataract which are based upon the epidemiologic studies conducted upon people (Nirmalan, Krishnadas, \& Ramakrishnan, 2003). But there is a limited in the availability of data for understanding the epidemiologic ARC features in Saudi Arabia (Wang, Lu, \& Qian, 2009). Most of these studies are conducted in other developed countries like European nations, Australia, Singapore, and USA (Hennis, Wu, Nemesure, \& Leske, 2004). There are few other relative studies in China due to the increase in the risk prevalence related to age-related cataract. But presently, there is no such study conducted in Saudi Arabia (Chang, Koo, \& Agron, 2011). Due to the rapidly changing elderly population and economic development in Saudi Arabia, these studies are not useful to assess the current prevalence of risk aspects related to the age-related cataract in Saudi Arabia (Gupta, Zheng, \& Ting, 2013). Therefore, there is an increased need to conduct the epidemiologic studies on the present condition associated with the age-related cataract in Saudi Arabia (Storey, Munoz, Friedman, \& West, 2013).

For matching this requirement, a study was conducted in the Prince Mohammed bin Nasser Hospital from $1^{\text {st }}$ April 2015 to $1^{\text {st }}$ February 2016. This research represents a population-oriented large scale prospective research which concentrates upon the incidences, prevalence, and risk aspects associated with the age-related cataract. The current stage of this cross-sectional research assessed the risk aspects and prevalence for the age-related cataract. This research also evaluates the prevalence of age-related cataract along with the cataract surgery outcomes in the Prince Mohammed bin Nasser Hospital eye study while comparing the results with the previous researches in Saudi Arabia and other nations.

\section{Methods:-}

\section{Study Design and Procedures:-}

For Prince Mohammed bin Nasser Hospital Eye Study, we conducted a baseline assessment related to the ophthalmology from April 2015 to February 2016. We also followed the random sampling method while creating a sampling frame with the help of geographically demarcated clusters. The sample size was 500 people which were aged 45 years or above. The recruitment material was handed over to all the targeted communities three to seven days before the survey. Every survey participant was self-identified and the research considered all the ethical considerations related to the identities of respondents. The generic consent of all the survey respondents was taken before going ahead with the study.

\section{Examination Procedure:-}

The survey respondents visited the nearby places for a physical check along with the complete ophthalmic examination. In case of physically disabled participants, their houses were visited. Post the registration of patients, a lot of medical examinations were conducted like measures related to the body fat percentage, body mass index, heart rate, and blood pressure. The collection of vein blood to conduct the genetic and serological analysis was carried out. The type of cataract in patients was identified followed by the conditions of the patients before and after the visual acuity tests. All kinds of surgical complications were measured which included the ocular comorbidities, uncorrected retina, PCO, and other surgical complications.

\section{Statistical Analysis:-}

For carrying out the data analysis, SPSS software was used. We managed to calculate the age as well as genderbased prevalence for all the types of cataract. This study was majorly based upon the population distribution data of Saudi Arabia. For achieving this, the standardized proportion of all the age and gender groups was measured as well as analysed for all the types of cataract. For analysing the categorical data, chi-square analysis was conducted where the differences were considered as significant if the p-value was less than 0.05 .

\section{Results and Discussion:-}

Out of the 500 respondents, 496 (response rate, 99.2\%) carried out the eye examinations. Considering the data, the mean age of the survey respondents was $63.74+/ 11.289$ (median 62; age range 22-96 years); There was higher count of males with male-to-female ratio as 292:204. Here, p-value was 0.341 which is greater than 0.05 . It leads to the conclusion that the chi-square test is not significant and the results are not occurring by chance. Moreover, there was further age and sex based studies for the types of cataracts. 


\begin{tabular}{|c|c|c|c|}
\hline \multicolumn{4}{|l|}{ Chi-Square Tests } \\
\hline & Value & $\mathrm{df}$ & Asymp. Sig. (2-sided) \\
\hline Pearson Chi-Square & $699.912^{\mathrm{a}}$ & 210 & .000 \\
\hline Likelihood Ratio & 150.363 & 210 & .999 \\
\hline $\mathrm{N}$ of Valid Cases & 500 & & \\
\hline
\end{tabular}

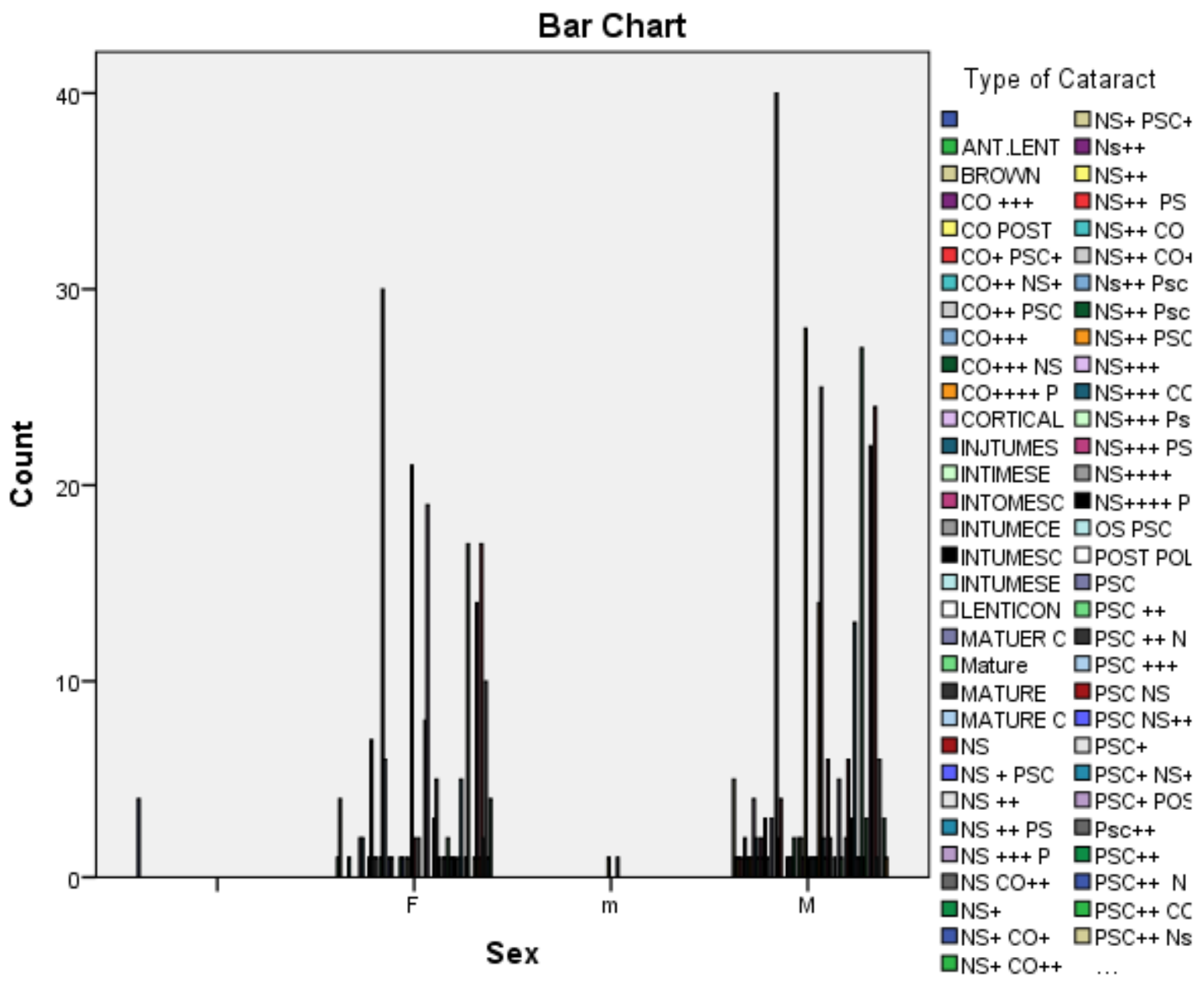

It was observed that only 64 males and 47 females exhibited nuclear sclerotic type of cataract which means that $21.92 \%$ males and $23.04 \%$ females were diagnosed with nuclear sclerotic cataract with different levels of their generation. At the same time, 67 males and 46 females displayed posterior subcapsular cataracts. It means that $22.95 \%$ males and $22.55 \%$ females were diagnosed with this kind of cataract. Moreover, 7 males and 2 females were suffering from the cortical cataract only. Though, the diagnosis of all these types of cataracts in pairs was also necessary to conduct a deep analysis over them. Therefore, people diagnosed with both nuclear sclerotic and posterior subcapsular cataracts were counted as 77 males and 48 females. The combination of both types of cataracts was found in these patients and their percentages in term of the male-to-female ratio can be given as $26.36 \%$ males and $23.53 \%$ females. Therefore, $125(25.2 \%)$ out of 496 respondents were diagnosed with the combination of both the cataracts. Moreover, there were 8 males and 4 females diagnosed with the combination of nuclear sclerotic and cortical cataracts. Finally, 9 males and 2 females were diagnosed with the combination of the posterior subcapsular and cortical cataracts. There were other types of cataracts in which it was observed that 60 males (20.55\%) and 54 females $(26.47 \%)$ were diagnosed with them.

In this case, the p-value was $0.00<0.05$ which means that chi-square test was significant and both the variables were dependent upon each-other. Therefore, gender influenced the occurrence of these types of cataracts. 


\begin{tabular}{|c|c|c|c|}
\hline \multicolumn{4}{|l|}{ Chi-Square Tests } \\
\hline & Value & $\mathrm{df}$ & Asymp. Sig. (2-sided) \\
\hline Pearson Chi-Square & $3397.570^{\mathrm{a}}$ & 3795 & 1.000 \\
\hline Likelihood Ratio & 1162.146 & 3795 & 1.000 \\
\hline $\mathrm{N}$ of Valid Cases & 496 & & \\
\hline
\end{tabular}

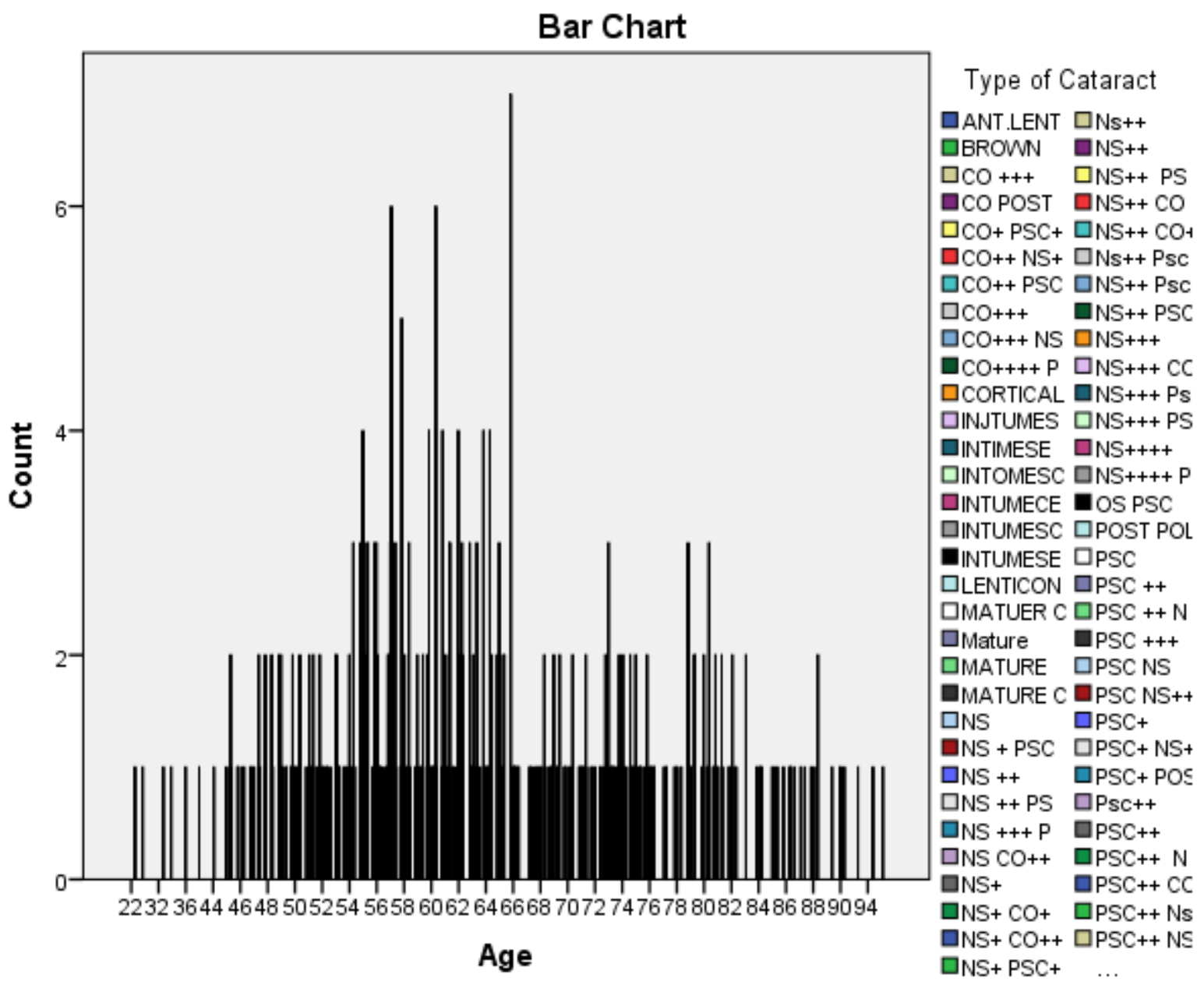

Though, gender provided a thorough view of the types of cataracts, it was important to relate them with the age as well. Here, for simplifying the data, the age groups were considered. These age groups ranged from 21-30 years (2 cases, $0.4 \%$ ), 31-40 years ( 3 cases, $0.6 \%$ ), $41-50$ years (31 cases, $6.25 \%$ ), 51-60 years (172 cases, 34.68\%), 61-70 years (135 cases, $27.22 \%$ ), $71-80$ years (93 cases, 18.75\%), 81-90 years (43 cases, $8.67 \%$ ), and $91-95$ years ( 3 cases, $0.6 \%)$. For only nuclear sclerotic cataract, maximum cases were observed in the age group of 51 to 60 years where 19 cases $(11.05 \%)$ were observed. At the same time, 16 cases $(17.2 \%)$ were observed in the age group of 71 to 80 years old people while 14 cases $(10.37 \%)$ were observed in the age group of 61 to 70 years. Moreover, there were 5 cases $(16.13 \%)$ in the age group of 41 to 50 years with 4 cases $(9.3 \%)$ in the age group of 81 to 90 years. There were two cases $(66.67 \%)$ of nuclear sclerotic cataract in the age group of 31 to 40 years.

There was further analysis for posterior subcapsular cataracts. In this case, 36 cases (20.93\%) were observed in the age group of 51 to 60 years. Moreover, 35 cases $(25.93 \%)$ were observed in the age group of 61 to 70 years. There were 15 cases in the both the age groups of 41 to 50 years $(48.39 \%)$ and 71 to 80 years $(16.13 \%)$. There were 8 
cases (18.6\%) in the age group of 81 to 90 years. Finally, 1 case was observed in each of the groups of 21 to 30 years $(50 \%), 31$ to 40 years $(33.33 \%)$ and 91 to 95 years $(33.33 \%)$.

We can avoid the other pair combinations due to their low level of prevalence but the combination of the NS and PSC is important for consideration due to high number of cases with this combination. In this case, there were 46 cases $(26.74 \%)$, in the age group of 51 to 60 years. Moreover, there were 32 cases (23.7\%) cases in the age group of 61 to 70 years. Also, 27 cases (29.03\%) were observed in the age group of 71 to 80 years. 12 cases (27.9\%) were observed in the age group of 81 to 90 years. There were 4 cases (12.9\%) for the age group of 41 to 50 years with 2 cases $(66.67 \%)$ for the age group of 91 to 95 years.

Here, the p-value was $1>0.05$ which means that the chi-square test was not significant and the data observed could be considered as happening by chance.

\begin{tabular}{|c|c|c|c|}
\hline \multicolumn{4}{|l|}{ Chi-Square Tests } \\
\hline & Value & $\mathrm{df}$ & Asymp. Sig. (2-sided) \\
\hline Pearson Chi-Square & $568.871^{\mathrm{a}}$ & 105 & .000 \\
\hline Likelihood Ratio & 118.301 & 105 & .177 \\
\hline $\mathrm{N}$ of Valid Cases & 500 & & \\
\hline
\end{tabular}

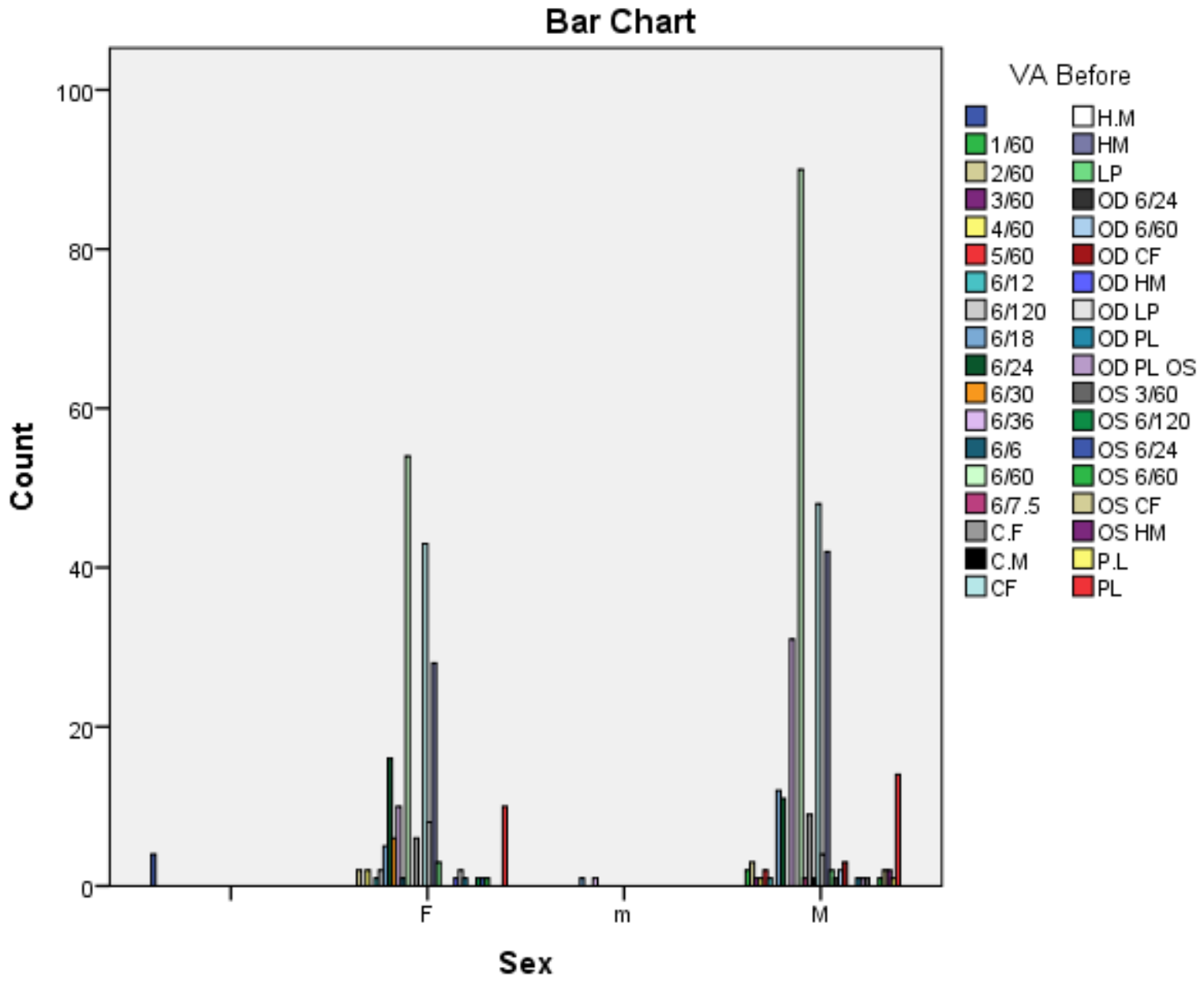

After conducting the chi-square analysis for the types of cataract, another analysis was conducted for the eye sights before and after visual acuity tests. Before visual acuity test, there were maximum cases $(144,29.03 \%)$ for the eye sight of 6/60 with 106(21.37\%) observations for count finger problems. There were $82(16.53 \%)$ observations for the hand motion problem. Moreover, there were 42 (8.47\%) observations for the eye sight of 6/36, $27(5.44 \%)$ observations for the eye sight of 6/24, and 18 (3.63\%) observations for the eye sight of 6/18. Rest of the aspects 
were not considerable for making any conclusion related to the research. In this case, the p-value was $0.000<0.05$ which means that chi-square test was significant and there is a considerable relationship between the gender and observations before the visual acuity examination.

\begin{tabular}{|c|c|c|c|}
\hline \multicolumn{4}{|l|}{ Chi-Square Tests } \\
\hline & Value & $\mathrm{df}$ & Asymp. Sig. (2-sided) \\
\hline Pearson Chi-Square & $532.340^{\mathrm{a}}$ & 54 & .000 \\
\hline Likelihood Ratio & 79.578 & 54 & .013 \\
\hline $\mathrm{N}$ of Valid Cases & 500 & & \\
\hline
\end{tabular}

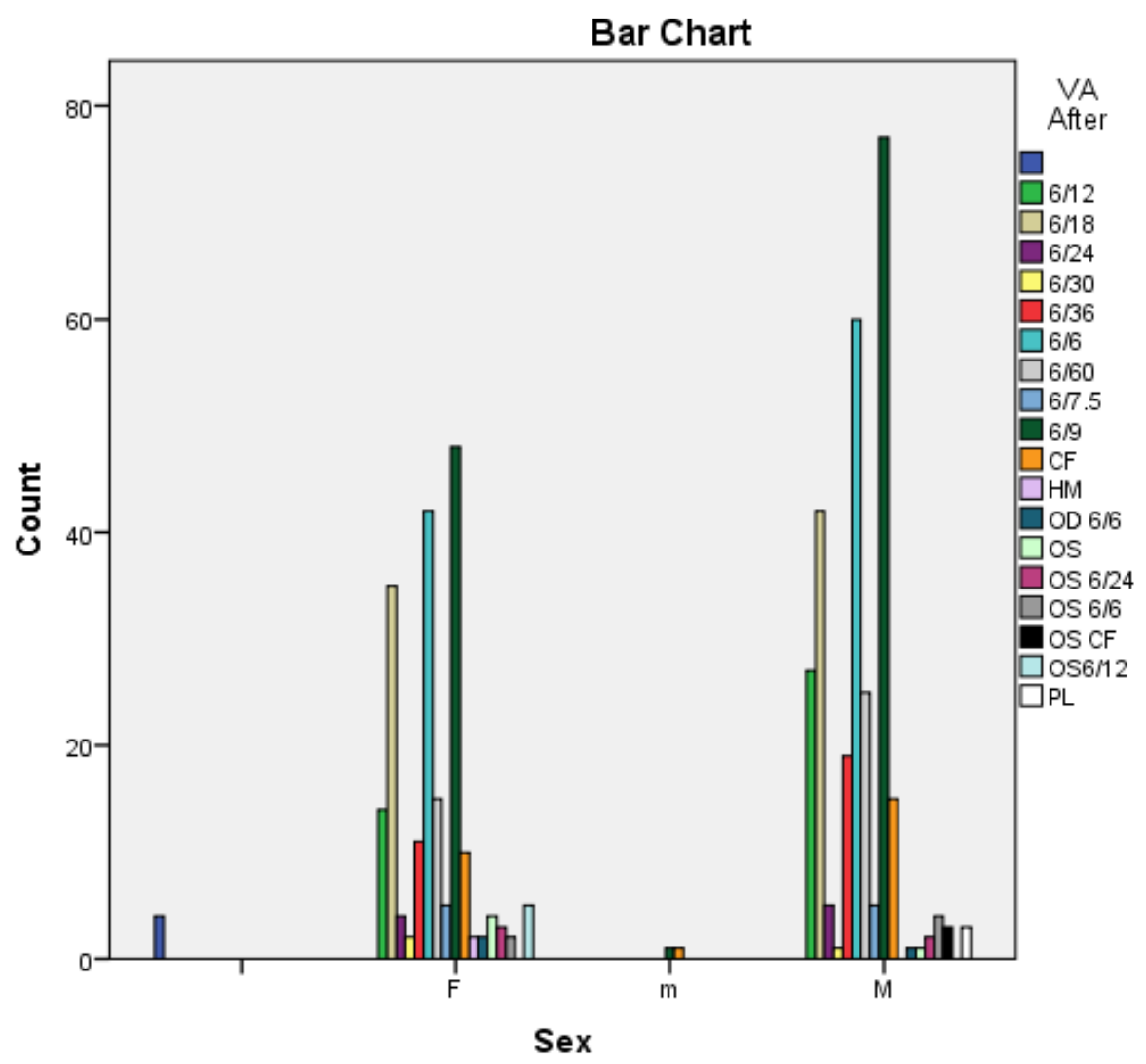

There was a drastic change in the results after VA test. It was observed that $126(25.4 \%)$ respondents were observed with an eye sight of 6/9. Moreover, there was a count of $102(20.57 \%)$ respondents with an eye sight of 6/6. 77 $(15.52 \%)$ people were observed with an eye sight of 6/18, $41(8.27 \%)$ people were observed with an eye sight of $6 / 12$, and $40(8.07 \%)$ people were observed with an eye sight of 6/60. Still, there were 26 cases $(5.24 \%)$ of problems with hand motion. Again, the p-value was $0.000<0.05$ which means that the chi-square test was significant and there is a relation between the gender and the conditions after the visual acuity test. It was observed that more number of males were observed with these conditions than females.

\begin{tabular}{|c|c|c|c|}
\hline \multicolumn{4}{|l|}{ Chi-Square Tests } \\
\hline & Value & $\mathrm{df}$ & Asymp. Sig. (2-sided) \\
\hline Pearson Chi-Square & $2047.147^{\mathrm{a}}$ & 1870 & .002 \\
\hline Likelihood Ratio & 715.123 & 1870 & 1.000 \\
\hline $\mathrm{N}$ of Valid Cases & 496 & & \\
\hline
\end{tabular}




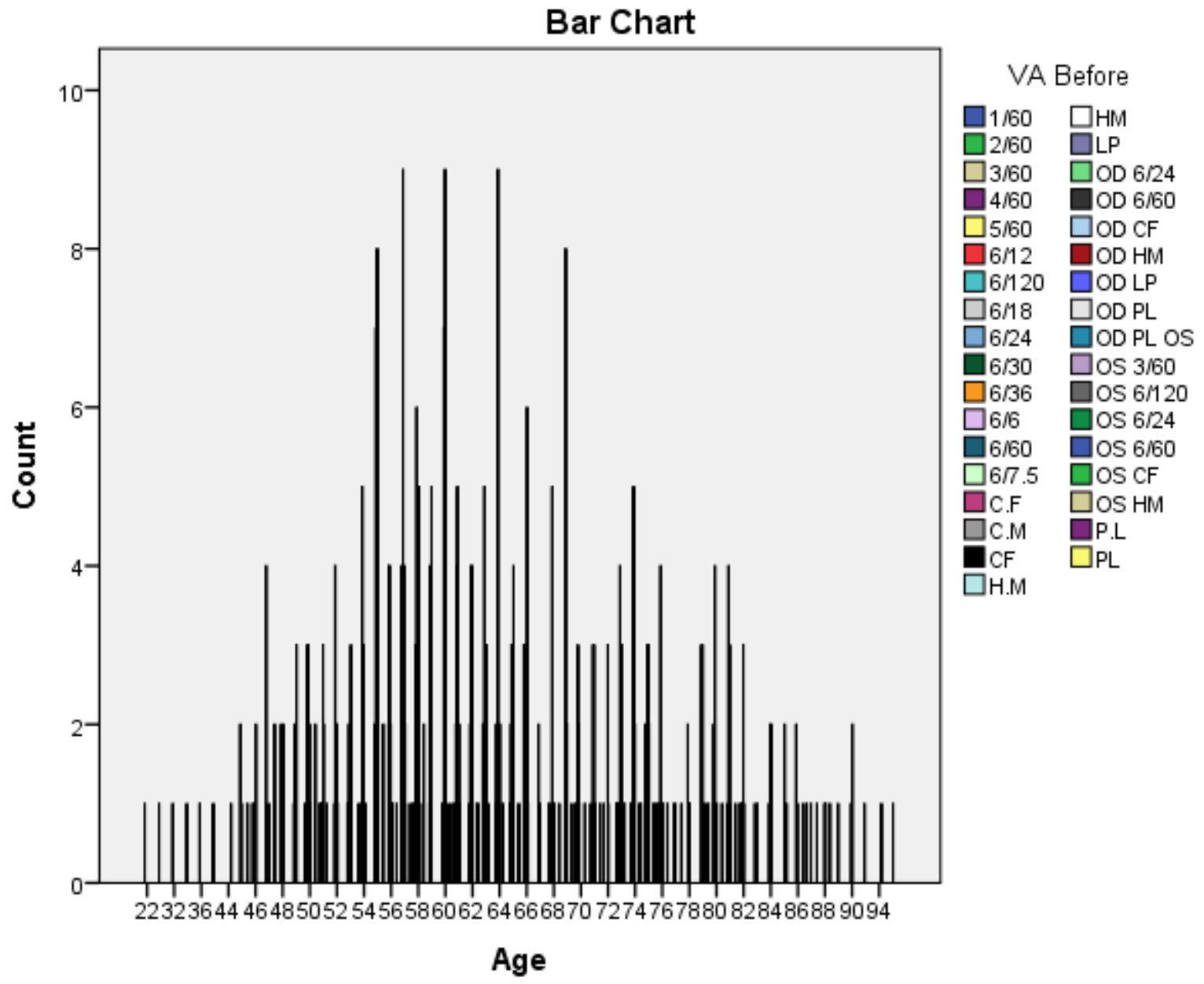

\begin{tabular}{|c|c|c|c|}
\hline \multicolumn{4}{|l|}{ Chi-Square Tests } \\
\hline & Value & $\mathrm{df}$ & Asymp. Sig. (2-sided) \\
\hline Pearson Chi-Square & $845.354^{\mathrm{a}}$ & 935 & .983 \\
\hline Likelihood Ratio & 547.513 & 935 & 1.000 \\
\hline $\mathrm{N}$ of Valid Cases & 496 & & \\
\hline
\end{tabular}




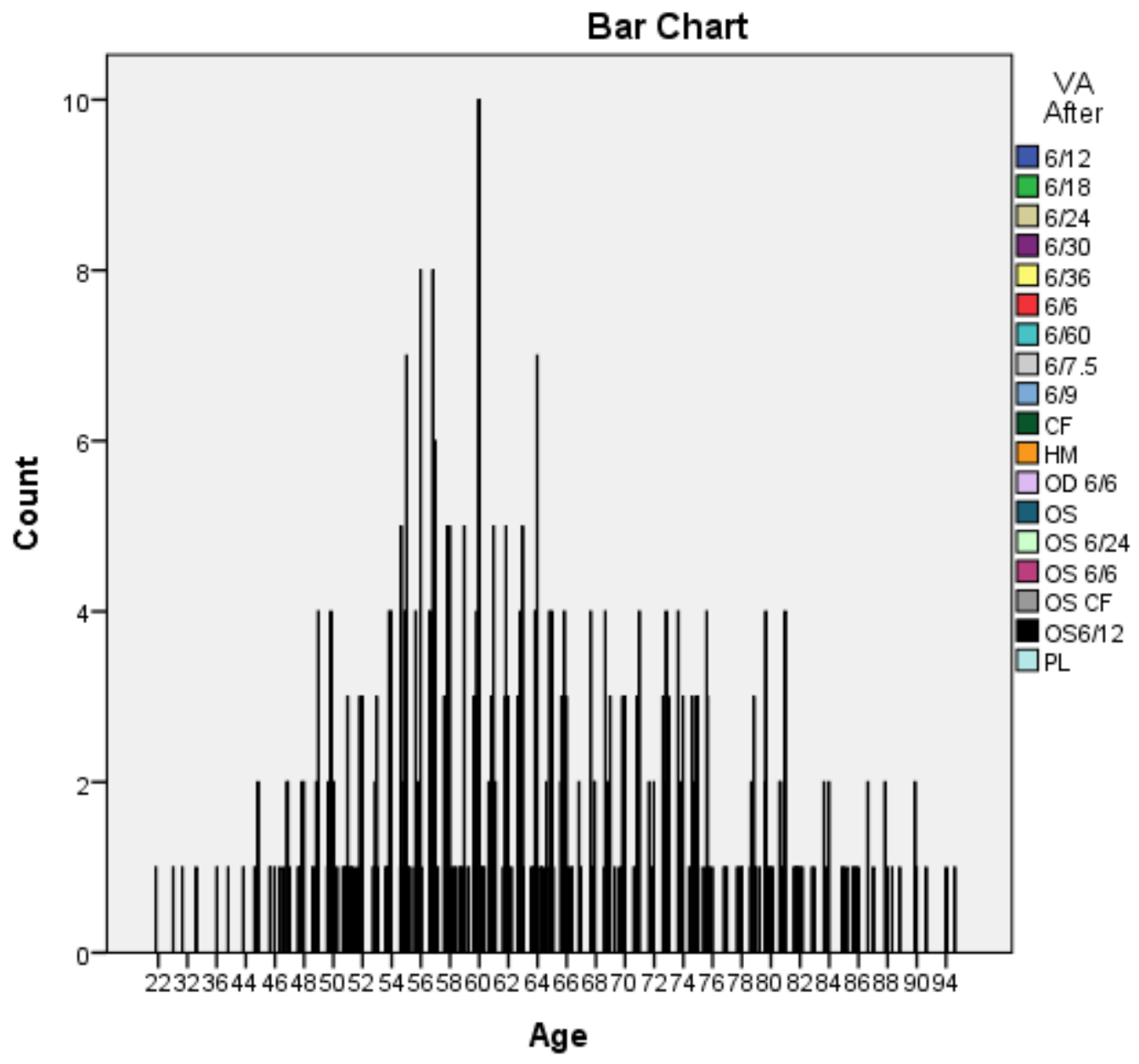

In case of age, for 144 cases of 6/60 eye sight before the VA test, 49 cases were observed for the age group of 51 to 60 years while 44 cases were observed for the age group of 61 to 70 years. Again, there were 29 cases for the age group of 71 to 80 years. For the count finger problems (104 cases), 44 were observed in the age group of 51 to 60 years. Moreover, 20 cases were observed for the age group of 71 to 80 years and 18 cases were observed for the age group of 61 to 70 years. Finally, there were 82 cases of hand motion problems where 29 cases were observed in the age group of 51 to 60 years and 22 cases were observed in the age group of 61 to 70 years. In this case, the p-value is $0.002<0.05$ which means that the chi-square test is significant and there is a relation between the age and the observations before the VA test. At the same time, the p-value for identifying the relation between the age and the observations after the VA test is $0.983>0.05$. It means that the chi-square test is not significant and the data could be a result of the events happening by chance.

\begin{tabular}{|c|c|c|c|}
\hline \multicolumn{4}{|l|}{ Chi-Square Tests } \\
\hline & Value & $\mathrm{df}$ & Asymp. Sig. (2-sided) \\
\hline Pearson Chi-Square & $448.326^{\mathrm{a}}$ & 132 & .000 \\
\hline Likelihood Ratio & 104.474 & 132 & .963 \\
\hline $\mathrm{N}$ of Valid Cases & 500 & & \\
\hline
\end{tabular}




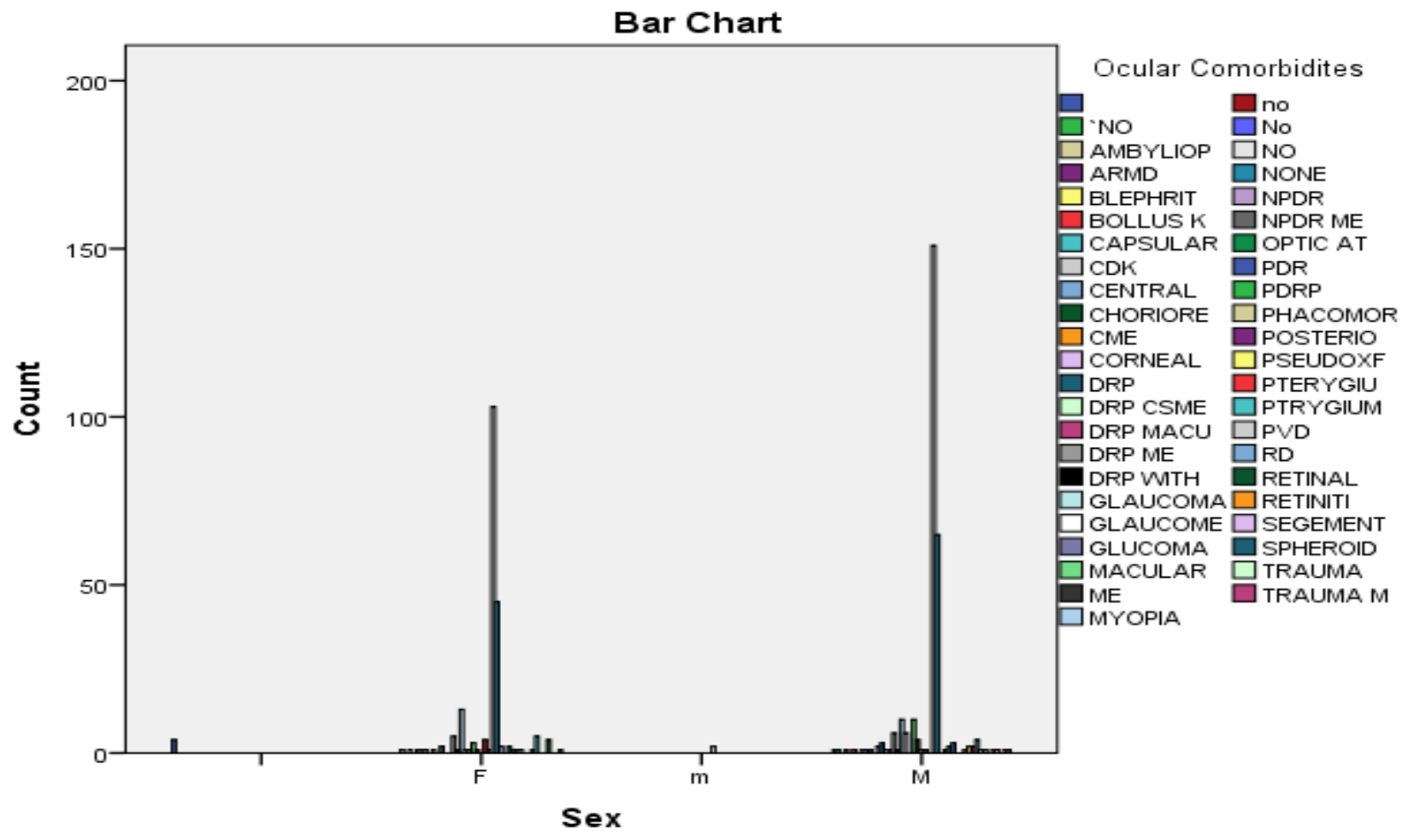

\begin{tabular}{|c|c|c|c|}
\hline \multicolumn{4}{|l|}{ Chi-Square Tests } \\
\hline & Value & $\mathrm{df}$ & Asymp. Sig. (2-sided) \\
\hline Pearson Chi-Square & $273.091^{\mathrm{a}}$ & 72 & .000 \\
\hline Likelihood Ratio & 66.625 & 72 & .657 \\
\hline $\mathrm{N}$ of Valid Cases & 500 & & \\
\hline
\end{tabular}




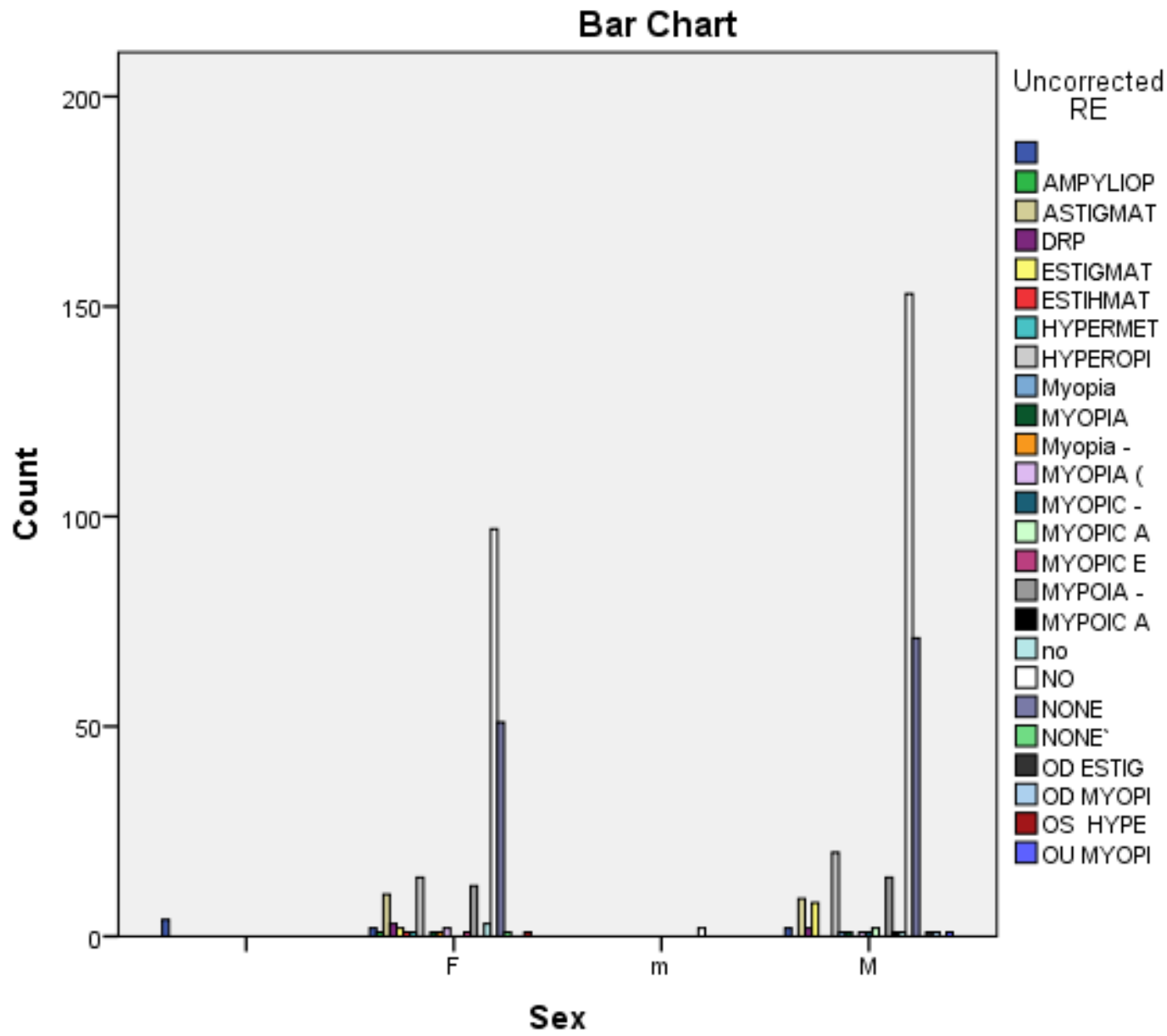

\begin{tabular}{|c|c|c|c|}
\hline \multicolumn{4}{|l|}{ Chi-Square Tests } \\
\hline & Value & $\mathrm{df}$ & Asymp. Sig. (2-sided) \\
\hline Pearson Chi-Square & $254.496^{\mathrm{a}}$ & 21 & .000 \\
\hline Likelihood Ratio & 43.771 & 21 & .003 \\
\hline $\mathrm{N}$ of Valid Cases & 500 & & \\
\hline
\end{tabular}




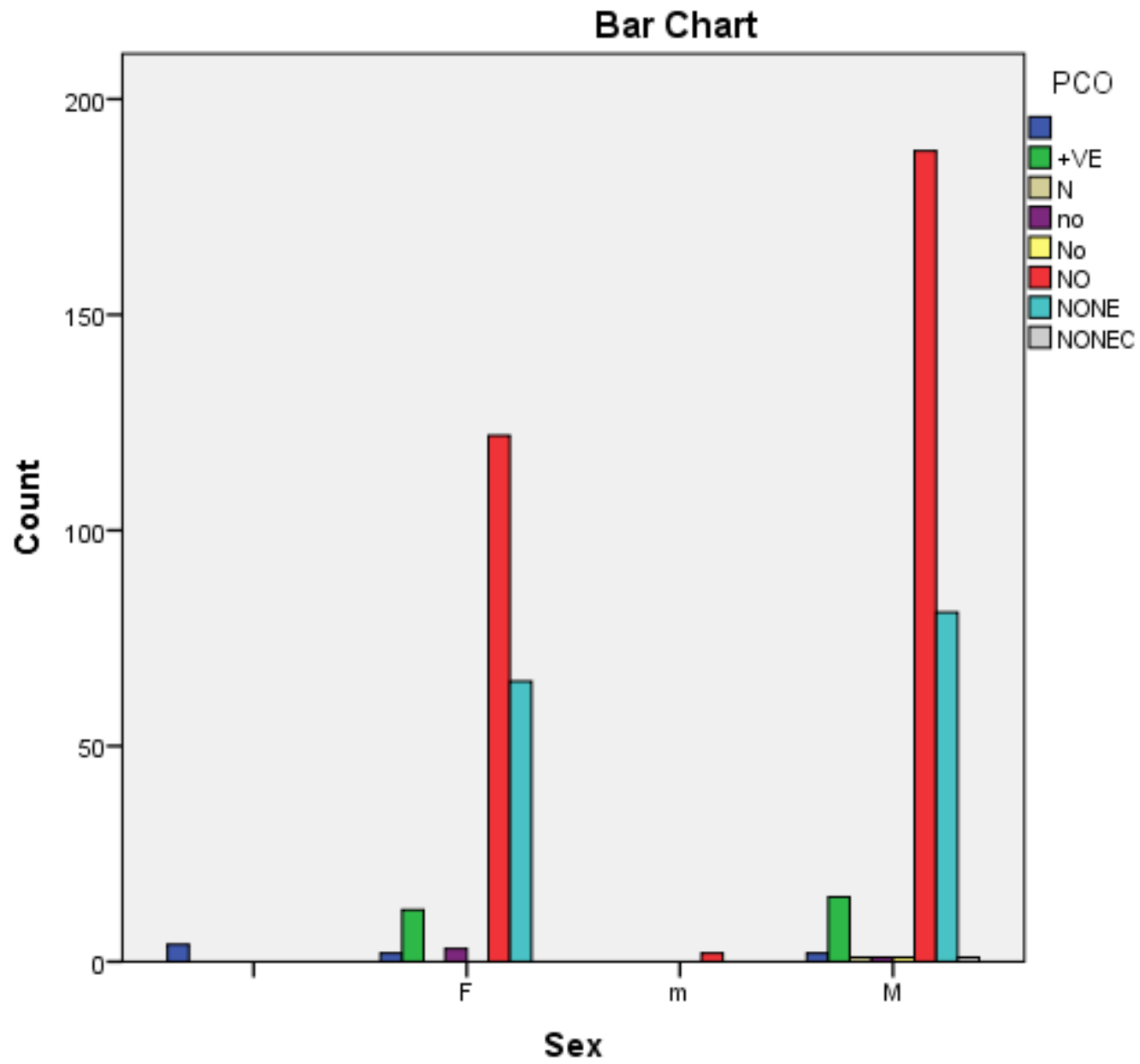

\begin{tabular}{|c|c|c|c|}
\hline \multicolumn{4}{|l|}{ Chi-Square Tests } \\
\hline & Value & $\mathrm{df}$ & Asymp. Sig. (2-sided) \\
\hline Pearson Chi-Square & $28.455^{\mathrm{a}}$ & 39 & .893 \\
\hline Likelihood Ratio & 27.672 & 39 & .912 \\
\hline $\mathrm{N}$ of Valid Cases & 500 & & \\
\hline
\end{tabular}




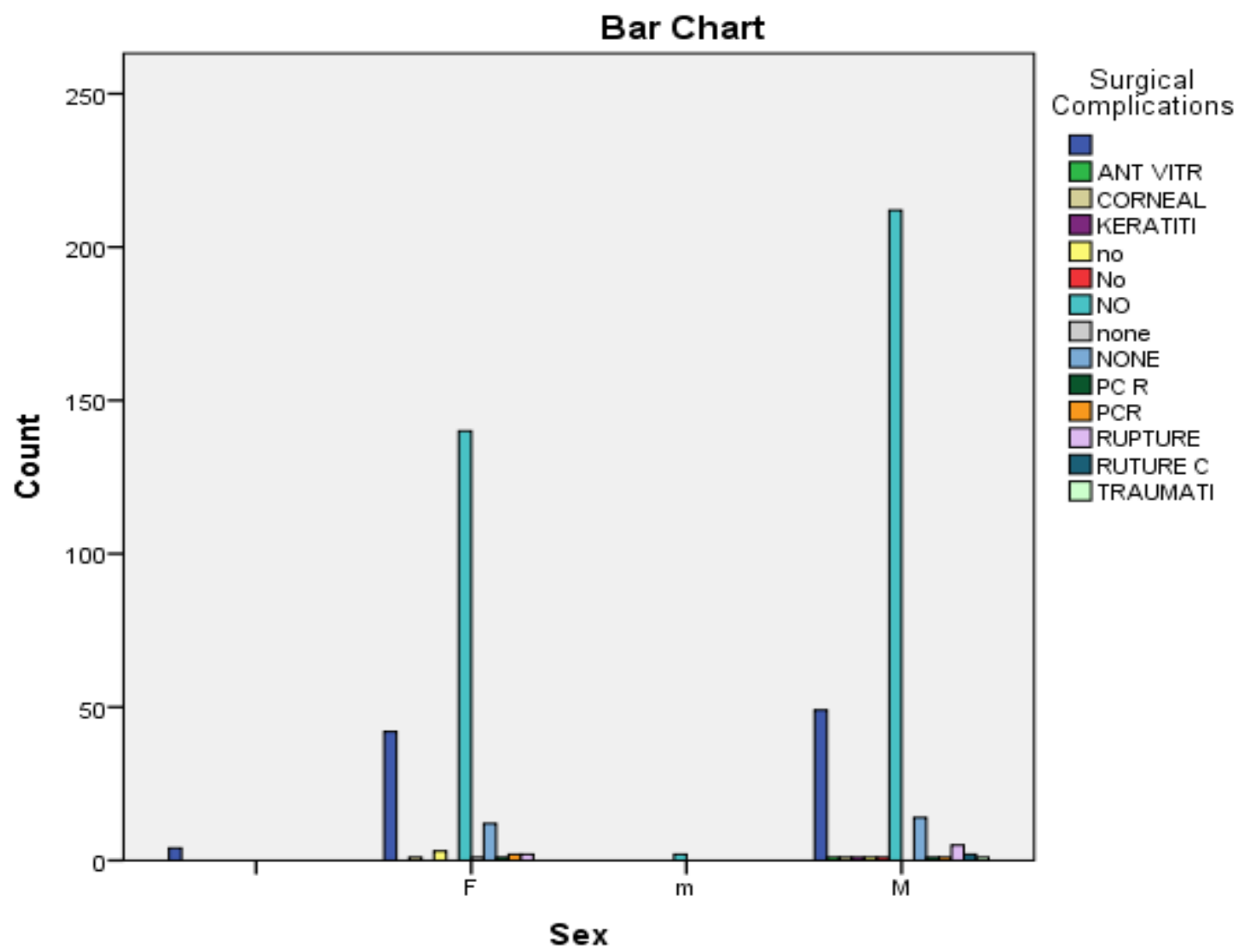

In terms of the complications, 373 people (75.2\%) did not observe any case of ocular comorbidites. Out of these people, 219 were males making it a percentage of $75 \%$ while 153 were females making it a percentage of $75 \%$. There were $31(6.25 \%)$ cases of glaucoma based problems which affected 16 males (5.48\%) and 15 females $(7.35 \%)$. Here, the p-value is $0.00<0.05$ meaning that the chi-square test is significant and there is a relation between the gender and ocular comorbidities. For uncorrected retina, 379 cases $(76.41 \%)$ were observed free from any discrepancies. Here, 227 males $(77.74 \%)$ and 152 females $(74.51 \%)$ were segmented from the total count. There were 34 cases (6.86\%) of hyperopia and 26 cases (5.24\%) of myopia. There were 19 cases $(3.83 \%)$ of astigmatism too. In this case, the p-value is 0.000 which is less than 0.05 . It means that the chi-square test is significant and there is a relation between the gender and uncorrected retina.

Apart from these two complications, there were 465 (93.75\%) negative outputs for the posterior capsule opacification. In this case, there were 275 cases $(94.17 \%)$ of males and 190 cases (94.06) of females. Also, 27 cases (5.44\%) people were found positive. Here. The p-value was $0.000<0.05$ which means that there is a relation between the gender and PCO. For surgical complications, 386 cases $(77.82 \%)$ were considered free from these complications. Here. The p-value was $0.893>0.05$ which means that chi-square test was not significant and the results are occurring by chance. Age was not a relevant factor for these complications due to the comparatively higher pvalue for all kinds of

\section{References:-}

1. Brian, G., \& Taylor, H. (2001). Cataract blindness - challenges for the 21st century. Bull World Health Organ, 249-256.

2. Chang, J., Koo, E., \& Agron, E. (2011). Risk factors associated with incident cataracts and cataract surgery in the Age-related Eye Disease Study (AREDS): AREDS report number 32. Ophthalmology, 2113-2119.

3. Gupta, P., Zheng, Y., \& Ting, T. (2013). Prevalence of cataract surgery and visual outcomes in Indian immigrants in Singapore: the Singapore Indian eye study. PLoS One.

4. Hennis, A., Wu, S., Nemesure, B., \& Leske, M. (2004). Risk factors for incident cortical and posterior subcapsular lens opacities in the Barbados Eye Studies. Arch Ophthalmol, 525-530. 
5. Klein, B., Klein, R., Lee, K., \& Gangnon, R. (2008). Incidence of age-related cataract over a 15-year interval the Beaver Dam Eye Study. Ophthalmology, 477-482.

6. Nirmalan, P., Krishnadas, R., \& Ramakrishnan, R. (2003). Lens opacities in a rural population of southern India: the Aravind Comprehensive Eye Study. Invest Ophthalmol Vis Sci, 4639-4643.

7. Rao, G., Khanna, R., \& Payal, A. (2011). The global burden of cataract. Curr Opin Ophthalmol, 4-9.

8. Richter, G., Chung, J., Azen, S., \& Varma, R. (2009). Prevalence of visually significant cataract and factors associated with unmet need for cataract surgery: Los Angeles Latino Eye Study. Ophthalmology, 477-482.

9. Storey, P., Munoz, B., Friedman, D., \& West, S. (2013). Racial differences in lens opacity incidence and progression: the Salisbury Eye Evaluation (SEE) study. Invest Ophthalmol Vis Sci, 3010=3018.

10. Wang, X., Lu, M., \& Qian, J. (2009). Rationales, design and recruitment of the Taizhou Longitudinal Study. BMC Public Health, 223. 